\title{
Seasonal Variation in Apparent Resistivity Probably Associated with Drastic Rainfall Changes in Southern Brazil
}

\author{
A. L. Padilha ${ }^{1}$, Í. Vitorello ${ }^{1}$, N. B. Trivedi ${ }^{1}$, M. J. Ribeiro ${ }^{2}$, and J. M. Gross ${ }^{2}$ \\ ${ }^{1}$ Instituto Nacional de Pesquisas Espaciais-INPE, C.P. 515, 12201 São José dos Campos-SP, Brazil \\ ${ }^{2}$ Companhia Brasileira de Cobre-CBC, Av. João Pessoa 155, 90040 Porto Alegre-RS, Brazil
}

(Received October 28, 1991; Revised July 11, 1992)

\begin{abstract}
Three scalar AMT campaigns were conducted in the mid-summer, late-fall, and late-winter seasons of 1990 in two nearby localities of southern Rio Grande do Sul State, Brazil. Comparisons of the results obtained at each season highlighted the problem of seasonal variation in the apparent resistivity measurements in the area. From 1-D inversions, the most striking fact in this temporal variation is the presence, in the last two campaigns, of a new deeper conductive layer (conductance of 6 to $7 \mathrm{~S}$ ) at depths of the order of $500 \mathrm{~m}$, which was not observed in the midsummer campaign. Careful observation of the regional rainfall data indicated that the seasonal conductive layer could be generated by the occurrence of a transitory deep aquifer that would grow or wane in time in accordance to the climatological conditions. Another likely explanation could be in terms of a misinterpretation of the geoelectrical section due to the distortion of the MT curves by induction effects generated by a saturated surficial layer.
\end{abstract}

\section{Introduction}

Marked changes in crustal apparent resistivity have been detected at many observation sites. These changes have been related to very different subsurface conditions such as in precursory earthquake signals (BARSUKOV, 1972; MAZzELLA and MoRRiSON, 1974; Sumitomo and Noritomi, 1986), salinity and temperature variations (HoNKURA et al., 1976), or changes in the near-surface groundwater level and ground temperature (XU, 1986). In this study, we report a possible association between large apparent resistivity seasonal variations and a drastic rainfall change in southern Brazil.

The study area (Fig. 1) is situated in the Rio Grande do Sul shield area of southern Brazil, where Early Paleozoic and Late Precambrian volcanic and almost horizontal sedimentary layers are underlain by metamorphic rocks and granitoids of the Precambrian basement. In this region, geophysical measurements were carried out at two locations: Santa Maria and Rodeio Velho. In the area of Santa Maria the fine sandstones and siltstones of the Mangueirão Member overlie the basement rocks and underlie the conglomerates, sandstones, and andesites of the Vargas Member. Both members belong to the Arroio dos Nobres Formation of the Bom Jardim Group. Mineral showings are predominantly found in the conglomerates and, in some cases, faults and fractures appear to control mineralization (TEIXEIRA et al., 1978). The predominant direction of faulting and fracturing has a northwest trend. In Rodeio Velho, a younger sequence of conglomerates, sandstones, and andesites of the Santa Bárbara and Rodeio Velho 


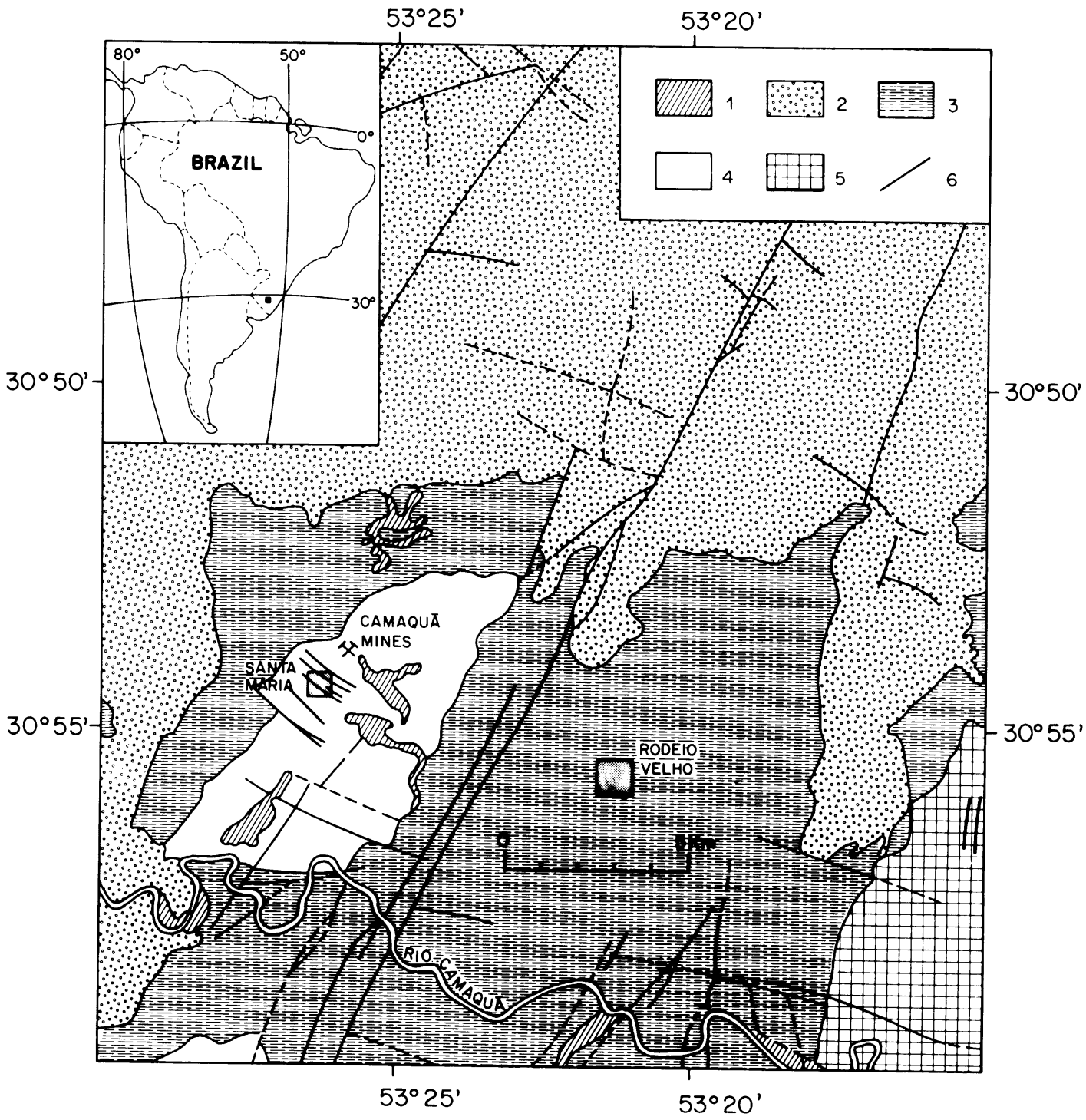

Fig. 1. Geological sketch of the study area (compiled from RiBEIRo and CARraro, 1971; TEIXEIRA et al., 1978), where: 1 - alluvium; 2 - Ordovician Guaritas Formation (Camaquã Group); 3 Ordovician Santa Bárbara Formation (Camaquã Group); 4 - Late Proterozoic-Early Paleozoic Bom Jardim Group; 5 - Precambrian basement complex; 6 - faults. The two regions where the measurements are concentrated (Santa Maria and Rodeio Velho) are also shown. 
members of the Camaquã Group, of very early Paleozoic age, overlies discordantly the Bom Jardim Group. Northwest-trending faults are also common in this area.

At both Santa Maria and Rodeio Velho areas, three scalar AMT surveys were conducted in the mid-summer, late-fall, and late-winter seasons of 1990. Apparent resistivities, for 12 log-equally spaced discrete frequencies from 8 to $4500 \mathrm{~Hz}$, were evaluated at 129 stations (21 in February, 28 in June, and 80 in September) using an equipment commercialized by EDA. A $20 \mathrm{~m}$ long dipole was employed for measuring the electric field whereas the magnetic field was measured with an induction coil. At each station, the measurements were carried out in two orthogonal directions, $\mathrm{N} 30^{\circ} \mathrm{E}$ and $\mathrm{N} 60^{\circ} \mathrm{W}$, respectively perpendicular and parallel to the general structural direction.

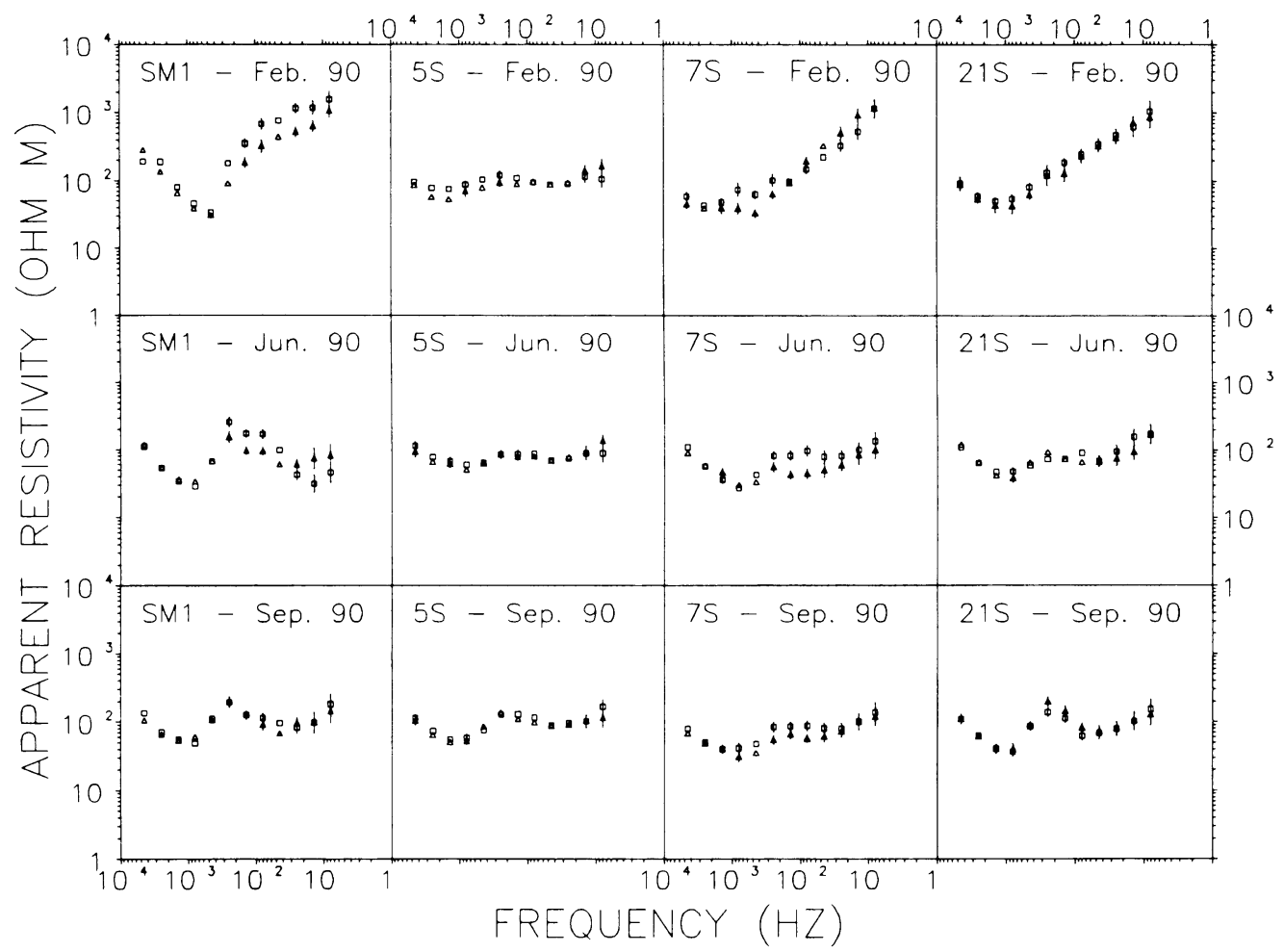

Fig. 2. Examples of AMT data obtained in February (upper graphs), June (intermediate graphs), and September (lower graphs). Squares correspond to the electric dipole in the $\mathrm{N} 60^{\circ} \mathrm{W}$ direction and triangles to the $\mathrm{N} 30^{\circ} \mathrm{E}$ direction. Station identified as SM1 is in Santa Maria and all the others in Rodeio Velho, following the number sequence described in the text. Error bars represent one standard deviation of apparent resistivity readings (not plotted when smaller than symbols). 


\section{Results}

Figure 2 exemplifies the AMT results obtained in this study. Apparent resistivities for the 12 analysed frequencies in the two orthogonal directions are shown in four stations for the three period of measurements. In Rodeio Velho, a gravity profile carried out previously by IPT/SP (Instituto de Pesquisas Tecnológicas do Estado de São Paulo) is available. Stations on the profile were spaced in $200 \mathrm{~m}$ on a roughly NS direction and have been numbered from $15 \mathrm{~N}$ to $27 \mathrm{~S}$, from north to south. Most of our AMT sites in Rodeio Velho were disposed nearly coincident to this profile, although not all the gravity stations have been occupied. In Santa Maria, the distribution of the measuring sites was more erratic, excepting in the third campaign where soundings were carried out on a grid 550 X $500 \mathrm{~m}$ long, respectively in NS and EW directions, and spacing between the stations of $50 \mathrm{~m}$ and $100 \mathrm{~m}$, respectively in the same directions (total of 72 sites).

The change in apparent resistivity curves between the different seasons can be easily seen in Fig. 2. In the mid-summer (February) soundings, at all but 2 of the 21 measured stations, AMT curves show an ascending branch that remain immutable for frequencies lower than $500 \mathrm{~Hz}$. Exceptions to this general behavior were observed at two stations of the Rodeio Velho area (at $5 \mathrm{~S}$ and at another site outside the gravity profile), one of them (5S) is shown in Fig. 2. These two stations exhibit a similar behavior to the ones of the second and third period of measurements (June, in latefall, and September, in late-winter). In these later campaigns, consistent deflections were observed at all sites in the apparent resistivity curves for frequencies lower than $200 \mathrm{~Hz}$ (see Fig. 2).

Examples of one dimensional (1-D) inversions (JuPP and VozofF, 1975) of apparent resistivity data are shown in Fig. 3. Station $21 \mathrm{~S}$ was chosen to represent the AMT results because one dimensionality is most typically supported with reliable data throughout the three campaigns at that station. It can be seen that in the first campaign, apparent resistivities could be inverted with a three-layered model, which includes a conductive layer (conductance of $2 \mathrm{~S}$ ) at a mean depth of $50 \mathrm{~m}$. On the other hand, in the two later campaigns the experimental data need a five-layered model to be adequately inverted. The same near-surface conductive layer is present as well as another deeper one (mean depth of $500 \mathrm{~m}$ ) with conductance of about $7 \mathrm{~S}$. In summary, our data seem to exhibit an apparent seasonally-related variation to which should be paid attention since similar situations might occur elsewhere, and that cannot be noticed in a single campaign.

\section{Discussions}

The problem of a recurrent conductive layer can be either actual, caused by changes in the upper crustal electrical properties, or fictitious, either due to problems during data acquisition or to distortional effects related to near-surface features.

Considering the observed variations of the apparent resistivity curves as representative of actual changes in local electrical properties, we searched for some seasonal effect that could be related to the conductivity distribution of the area. Since the electrical properties of sedimentary rocks are strongly dependent on the presence of 

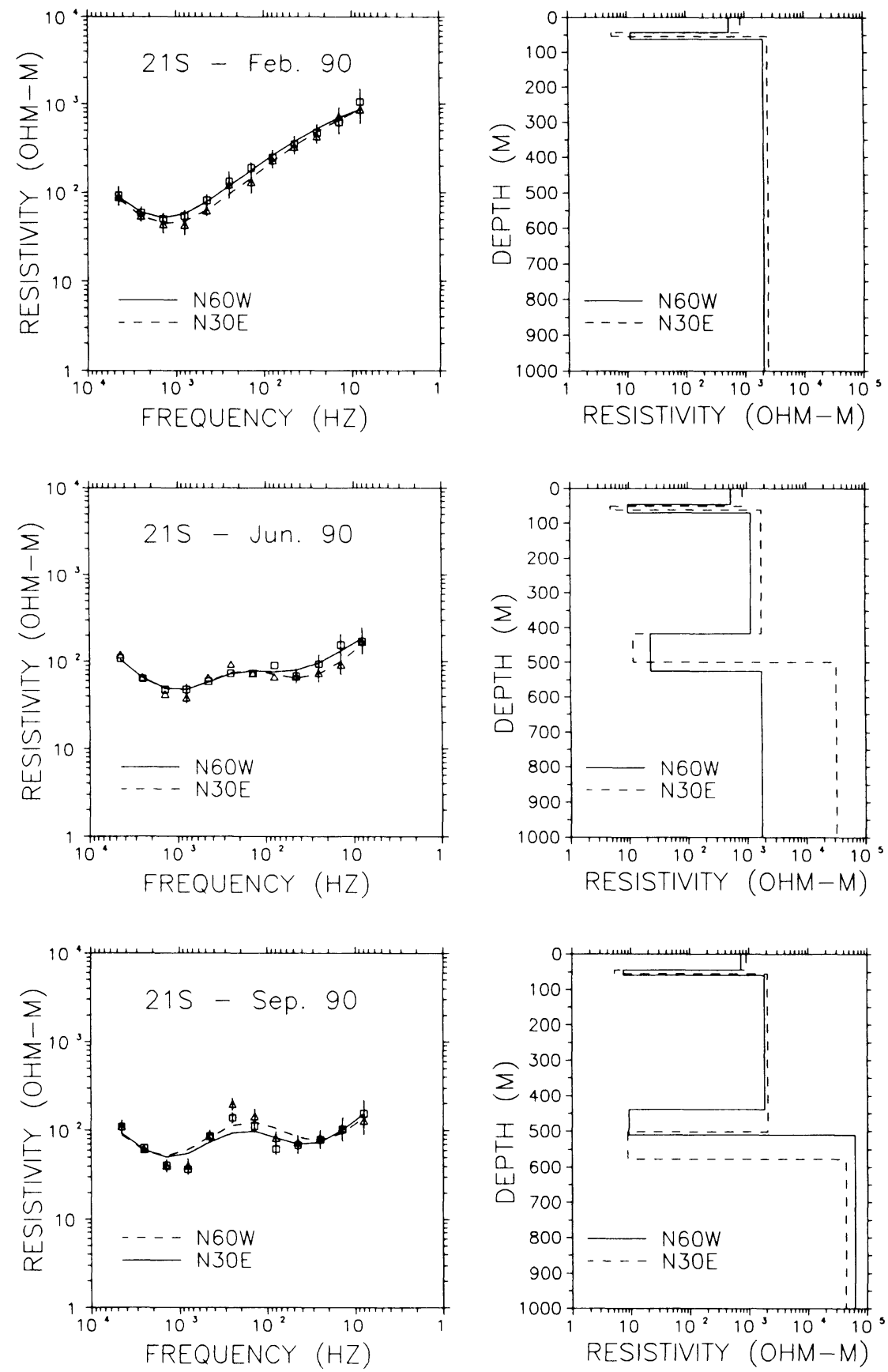

Fig. 3. Example of the inversion of AMT data. At left, the observed data at station $21 \mathrm{~S}$ in the three periods of measurements; at right, the best-fitting 1-D layered-earth models that explain the observations. 
water (Keller and FrischKnecht, 1966; Olhoeft, 1980), we looked first at coincident seasonally-related climatological changes. Figure 4 shows the rainfall distribution in the period from January, 1988 to September, 1990 in stations Porto Alegre, Santa Maria, and Bagé, respectively $240 \mathrm{~km} \mathrm{NE}, 140 \mathrm{~km} \mathrm{NNW}$, and $75 \mathrm{~km} \mathrm{SW}$ of the study area. The figure shows the absolute monthly precipitation for the three stations and makes a comparison with the expected rainfall monthly mean, calculated from available data in the period 1931-1960. It can be observed that specifically at Bagé station, which is the station nearer to the measurement sites and which also presents the same pluviometric features as the study area, the period from the beginning of 1988 to January, 1990 was characterized by a severe drought. Although the expected total precipitation through the period was $2571.2 \mathrm{~mm}$, it was only registered $1650.5 \mathrm{~mm}$, an accumulated deficit of $36 \%$. Comparing to the two other meteorological stations in the region, the observed total rainfall in the same period was $3101.8 \mathrm{~mm}$ and $2376.1 \mathrm{~mm}$, respectively at Santa Maria and Porto Alegre.

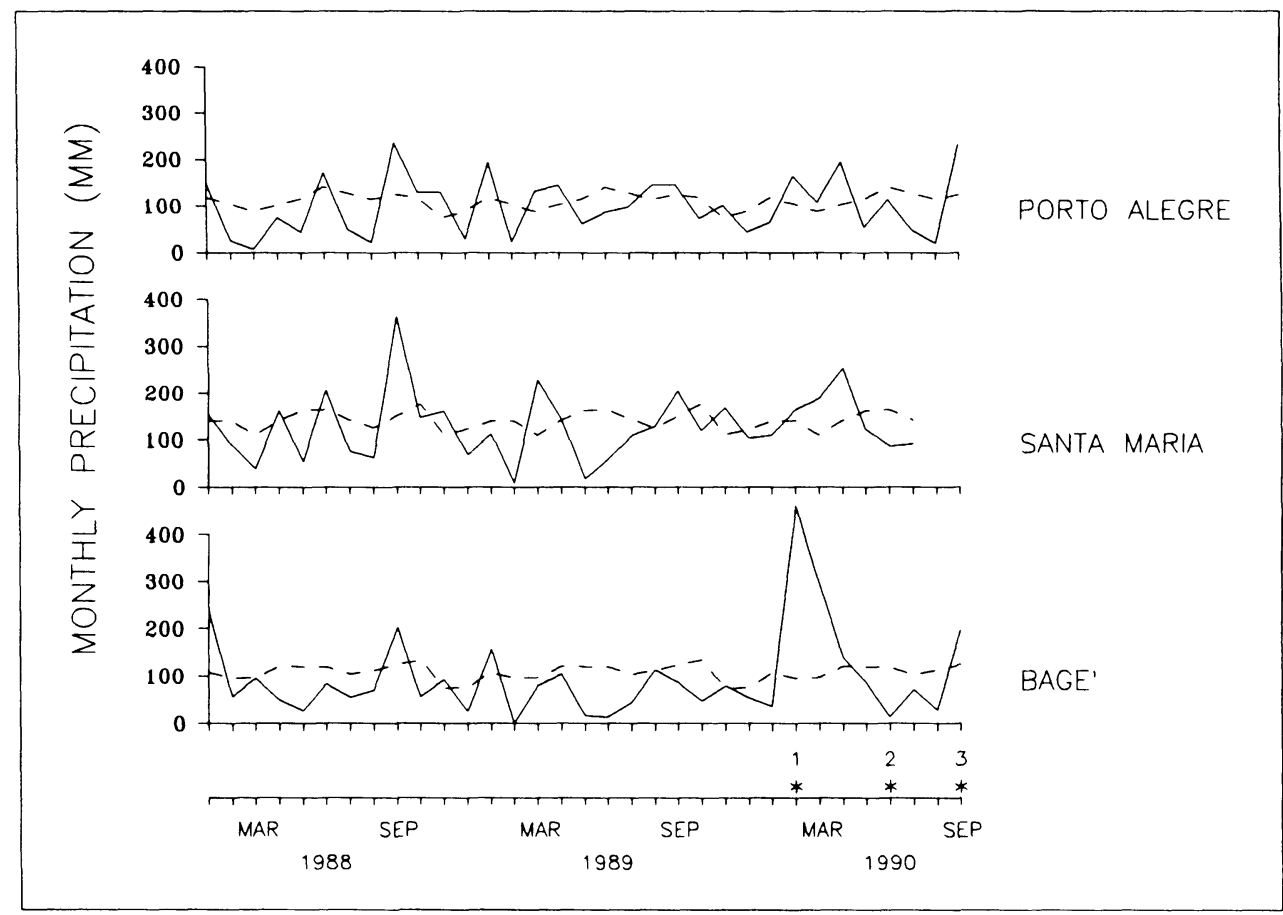

Fig. 4. Total monthly rainfall in the period from January, 1988 to September, 1990 for three meteorological stations in southern Brazil. Continuous lines are referred to observed data in the period and dashed lines to the monthly historical mean at each station. Asterisks with numbers attached to the month axis correspond to the present first, second and third periods of AMT observations.

After January, coinciding with the beginning of our campaigns, there was a reversed situation, with a clear rainfall excess in the period from February to May, 1990, which is the period between our two first surveys. The accumulated rainfall 
excess in this period was of $546.7 \mathrm{~mm}$ (total observed precipitation of $979.8 \mathrm{~mm}$ ). In Santa Maria and Porto Alegre, the observed total rainfall in the same period was $729.2 \mathrm{~mm}$ and $521.3 \mathrm{~mm}$, respectively. From the second to the third campaign, it was recorded another period with minor rainfall in the Bagé region (recorded precipitation of $310.2 \mathrm{~mm}$ ), generating a small deficit of $149.5 \mathrm{~mm}$.

This major variation in rain precipitation and its close agreement with the observed temporal variation of the electrical resistivity in the area of our study brings on the supposition of a direct relation between the two phenomena. The appearance/disappearance of the deeper conductive layer could be then related, for instance, to the occurrence of a deep aquifer in the region, which could dwindle during a dry spell and expand after a rainy period. The large drought which affected the region just before our first campaign, would cause the water waning responsible for the change in resistivity of the layer at that depth. Additional evidences for the possible existence of this deep aquifer come from a stratigraphic well drilled in the Camaquã Mines, near the Santa Maria site (see Fig. 1). This well attained the depth of $1200 \mathrm{~m}$, without arriving to the basement of the sedimentary layers composed of alternating sandstones and siltstones. The aquifer could be situated in one of the more permeable sandstone layers, sealed off either by siltstones or by impermeable sandstones.

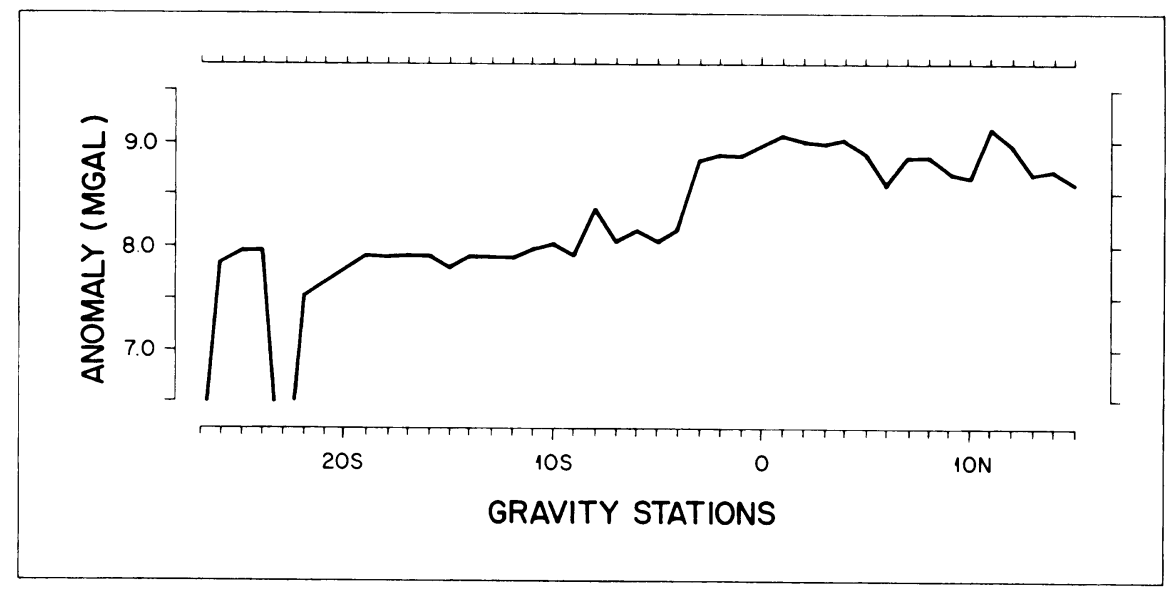

Fig. 5. Residual gravity profile in roughly NS direction in Rodeio Velho region. Interval between gravity stations is of $200 \mathrm{~m}$.

However, to have in June, at a mean depth of $500 \mathrm{~m}$, an aquifer generated by the February rainfall, we must have a velocity of groundwater flow greater than $4 \mathrm{~m} /$ day. It is extremely improbable that such a fast permeation of precipitation could normally be attained by the rocks of the study area. Another mechanism must be present to control the water penetration to the underground. Possible signatures of this mechanism can be found on the available gravity data and on the exceptional AMT soundings (specially the $5 \mathrm{~S}$ ) which exhibit the presence of the second conductive layer in the summer season. 
Figure 5 shows the residual gravity profile conducted earlier by IPT/SP in the region of Rodeio Velho. It can be seen that, between $3 \mathrm{~S}$ and $4 \mathrm{~S}$ on the profile, there is an abrupt variation, about $1 \mathrm{mGal}$, in the gravity anomaly. This step is probably caused by the presence of a fault, cutting across the sedimentary rocks. Sounding $5 \mathrm{~S}$ is situated from 200 to $400 \mathrm{~m}$ south of this fault and could have been showing, already in the beginning of the rainy season in February, the deep aquifer, favored by a faster recharge conduit facilitated by the probable fault zone.

The recharging of the postulated aquifer through a system of vertical faults brings out other questions for consideration. The first one is the necessity of finding similar mechanisms of vertical water propagation all over the study region. Vertical faults must be widely disseminated and at depth lateral flowing of the descending water must occur at nearly the same depths everywhere. Also, it would be quite interesting to verify what have happened over the fault zone (stations $3 \mathrm{~S}$ and $4 \mathrm{~S}$ ) and at its northern side (station $2 \mathrm{~S}$ ) in the February period. Unfortunately, the absence of reliable AMT data in our first campaign in that region and the lack of hydrogeological information prevent a more careful discussion on these points.

Regarding the hypothesis of a misinterpretation of the local geoelectrical structure, problems of data acquisition generating unreal layers is intrinsic to the MT method. Following REDDY et al. (1976), a main disadvantage of the MT method when applied to the detection of changes of the crustal resistivity is related to the limited knowledge on the effect of sources and their long-time variations on the magnetotelluric fields. In the audio-frequencies, the principal source of natural electromagnetic energy are electrical discharges during lightning storms. Disturbances generated by signal sources on AMT measurements were discussed by LAKANEN (1986) for soundings carried out in a high latitude region (Finland). However, from previous AMT surveys in Brazil (Hoover and Pierce, 1984; PAdilha et al., 1989), it seems that the soundings carried out in the country are not affected in a similar way. In fact, most of the data can be considered reliable with good repeatability, which can probably be associated with the high signal level due to the relative proximity of the equatorial lightnings and the low artificially generated noise due to the remoteness of the studied areas.

Specifically in the soundings reported here, data acquisition problems were observed only during the third period of measurements (late-winter). Analogously to what was previously observed by LAKANEN (1986), AMT results in our study were disturbed by the passage of meteorological frontal systems over the area. Because of that, half of the 80 soundings were carried out anew, to obtain more reliable data. It should be mentioned that in these disturbed stations, we observed basically alterations in the DC level of the curves, generating misinterpretations in the thickness and conductivity of the different layers during the inversion. However, the minimum number of layers necessary to model the data did not change.

The other possibility of generating a fictitious conductive layer in a geoelectrical section is related to the distortion of the MT curves by near-surface effects (Berdichevsky and Dmitriev, 1976; MAReschal et al., 1991). Berdichevsky and DMITRIEV (1976) showed that induction effects are excited in the presence of inhomogeneities by excessive currents. As a consequence, ascending branches of MT curves are distorted (divided by a minimum caused by the influence of lateral zones of lower resistivity). Formal interpretation of these distorted curves misrepresents the geoelectrical section by introducing a false conductive layer. The effect is most prominent in 
the TE (transverse electric) curves and, in tensorial soundings and in the simplest situations, it is sufficient to compare TE and TM (transverse magnetic) curves to detect its presence.

Induction effects were identified near water-filled fractures through a geoelectrical study in the Baikal region (BERDICHEVSKY et al., 1980). In our study area, a similar effect could be generated by lateral variations in the properties of a saturated surficial layer (first tens of meters). In order to strictly examine the validity of this hypothesis, it should be necessary a more thorough study, with more observation sites covering the region and the determination of not scalar but tensor impedances.

\section{Conclusions}

The major importance of the findings in this study is related to its possible application in other areas subjected to similar rainfall and hydrogeological conditions. In these localities, MT measurements should be avoided after the rainy season, particularly when the principal objective is the study of the conductivity distribution in the lower crust. In these cases, the possible modelling of a near surface conductive layer associated either with a bulged aquifer or with lateral distortional effects may attenuate or distort the propagation of the electromagnetic signals, affecting the interpretation of deeper conductive layers. On the other hand, measurements carried out after the rainy season are recommended when the intention is to determine the depth and thickness of a possible aquifer. Also, the detection of fault zones is important in groundwater exploration because of their recharge capabilities.

To fully understand the intricate geoelectrical properties in the study area, additional geophysical and hydrogeological data would be necessary. These data would permit us to discern between the two proposed hypotheses for the deeper conductive layer: deep aquifer or near-surface lateral effects. In any way, it seems that there is no doubt on the relation between the observed seasonal apparent resistivity variation and the drastically variable local pluviometric regime.

We are grateful to Domingos Fonseca, from INPE, for his help in the acquisition of AMT data, to Custodio Simonetti, from the 8th Meteorological District of Porto Alegre, for the prompt supply of meteorological data, to Vicente Galli, IPT/SP, for access to his gravity data, and to Henrique Anawate, President of $\mathrm{CBC}$, for his company support in the field. Thanks are also due to Olivar Lima and Joaquim Cerqueira Neto, from Universidade Federal da Bahia, for constructive criticisms on a previous interpretation of the data and to the two anonymous reviewers for their valuable comments.

\section{REFERENCES}

BARSUKOV, O. M., Variations of electric resistivity of mountain rocks connected with tectonic cause, Tectonophysics, 14, 273-277, 1972.

Berdichevsky, M. N. and V. I. DMitriev, Basic principles of interpretation of magnetotelluric sounding curves, in Geoelectric and Geothermal Studies, KAPG Geophys. Monogr., edited by A. Ádám, pp. 165-221, Akadémiai Kiadó, Budapest, 1976.

Berdichevsky, M. N., L. L. Vanyan, V. A. Kuznetsov, V. T. Levadny, M. M. Mandelbaum, G. P. Nechaeva, B. A. Okulessky, P. P. Shilovsky, and I. P. Shpak, Geoelectrical model of the Baikal region, Phys. Earth Planet. Inter., 22, 1-11, 1980. 
Honkura, Y., E. R. Niblett, and R. D. Kurtz, Changes in magnetic and telluric fields in a seismically active region of eastern Canada: preliminary results of earthquake prediction studies, Tectonophysics, 34, 219-230, 1976.

Hoover, D. B. and H. Pierce, Results of audiomagnetotelluric and telluric surveys in the northern border of the Chapada Diamantina, Bahia, Brazil, Unpubl. Rep., Comp. Baiana de Pesq. Min., 38 pp., 1984.

Jupp, D. L. B. and K. Vozoff, Stable iterative methods for the inversion of geophysical data, Geophys. J. R. astr. Soc., 42, 957-976, 1975.

Keller, G. V. and F. C. FrischKnecht, Electrical Methods in Geophysical Prospecting, 517 pp., Pergamon, New York, 1966.

LAKANEN, E., Scalar audiomagnetotellurics applied to base-metal exploration in Finland, Geophysics, 51, 1628-1646, 1986.

Mareschal, M., R. D. Kurtz, M. Chouteau, and R. Chakridi, A magnetotelluric survey on Manitoulin Island and Bruce Peninsula along GLIMPCE seismic line J: black shales mask the Grenville Front, Geophys. J. Int., 105, 173-183, 1991.

Mazzella, A. and H. F. MorRison, Electrical resistivity variations associated with earthquake on the San Andreas fault, Science, 185, 855-857, 1974

Olhoeft, G. R., Electrical properties of rocks, in Physical Properties of Rocks and Minerals, edited by Y. S. Touloukian, W. R. Judd, and R. F. Roy, pp. 257-330, McGraw-Hill, New York, 1980.

Padilha, A. L., N. B. Trivedi, J. M. da Costa, Í. Vitorello, A. Dupis, and C. Cavoit, Audiomagnetotelluric study in northeast region of Paraná basin, South America, Geophysics, 54, 824-831, 1989.

Reddy, I. K., R. J. Phillips, J. H. Whitcomb, D. M. Cole, and R. A. Taylor, Monitoring the time dependent electrical resistivity by Magnetotellurics, J. Geomag. Geoelectr., 28, 165-178, 1976.

Ribeiro, M. and C. C. Carraro, Geotectonic map of the Caçapava do Sul region - RS, Brazil, Tech. Rep. Inst. Geociências - UFRGS, map, 1971.

Sumitomo, N. and K. Noritomi, Synchronous precursors in the electrical earth resistivity and the geomagnetic field in relation to an earthquake near the Yamasaki fault, Southwest Japan, $J$. Geomag. Geoelectr., 38, 971-989, 1986.

Teixeira, G., A. P. Gonzales, M. A. Gonzales, and O. A. B. Licht, Situação das Minas do Camaquã, Rio Grande do Sul, Proc. 30th Cong. Bras. Geologia, Recife, 1893-1905, 1978.

$\mathrm{XU}, \mathrm{S}-z .$, Quantitative estimation of an annual variation of apparent resistivity, J. Geomag. Geoelectr., 38, 991-999, 1986. 